\title{
Teacher librarians a tour de force for information literacy in Hong Kong schools: Reality or rhetoric?
}

\author{
James Henri \\ Associate Professor \\ The Faculty of Education \\ The University of Hong Kong \\ Wah Hing Betty Chu \\ Part-time Tutor HKUSPACE, University of Hong Kong \\ Commissioner, Hong Kong Teacher Librarians' Association \\ Teacher Librarian \\ Tsing Yi Trade Association Primary School
}

\section{Background:}

The process of curriculum reform in Hong Kong schools has been an ongoing process since 1998. This reform has been largely driven by the catch phrase 'learning to learn' and has demanded a more student centered curriculum and pedagogy. Essential ingredients in this reform have been the demand for better qualified teachers, for IT savvy teachers, and for teachers and students who are able to effectively use information to solve problems.

Perhaps not surprisingly, the teacher librarian and information services to schools were identified as key ingredients in the change process. Indeed, whereas a decade ago very few schools were equipped with a central library, today almost all schools have one. Likewise a decade ago few schools employed a teacher librarian where as today the post of teacher librarian is one of only two mandated positions in schools; the other being the principal. In addition, all newly appointed teacher librarians are required to complete a two year part time Diploma in Teacher Librarianship that is paid for by the employing authority (although participating teacher librarians face a modest course fee). Participating teachers are allocated time release to support their participation in the program.

The appointment since 2002 of a Primary School Master/Mistress Curriculum Development (PSMCD) has strengthened the possibility of implementation of curriculum reform at the school level. These positions are filled by respected teachers who serve on a five year contract basis. It is expected that the PSMCD would work closely with the teacher librarian. Since 2006 the PSMCD has been established as a permanent post with their authority and leadership clearly articulated by the EMB. The 
school must enable the PSMCD to dedicate a substantial proportion of time to the position and the number of timetabled lessons that the PSMCD can teach must be strictly controlled.

A concurrent component of school reform in Hong Kong has been the provision of a larger measure of school based management and accountability with principals taking on greater responsibilities than in the past. Anecdotal evidence suggests that many principals have found creative ways to make use of the teacher librarian beyond those important functions outlined in the policy documents. Indeed it is suggested that many teacher librarians are actually full time subject teachers with an added responsibility of supervision of the library.

\section{The Study:}

The purpose of the study was to identify the extent to which policy is being implemented at the school level. The researchers identified best practice as given by the Employment and Manpower Bureau policy in the process of education reform, with respect to school libraries and teacher librarians. All newly appointed teacher librarians were invited to complete an instrument to identify current practices such as: the amount of time devoted to the role of teacher librarian, a ranking of the importance attached to teacher librarian tasks, a sample time table to identify how teacher librarians were scheduled, the number and range of subjects taught by teacher librarians, examples of interactions and interventions with subject teachers, relationship with principal and so on. These data were analyzed to develop benchmarks of practice and compared to the expected practice identified by the employing authority. Ten teacher librarians were selected as case studies of actual practice. Semi structured interviews and site visits were used to further explore actual practice and the degree of change that had occurred at the school level. Five of the case studies involved newly appointed teacher librarians who were undertaking the diploma in teacher librarianship, and five involved experienced and qualified teacher librarians. The case studies identify actual practice as opposed to expected practice. In addition, the case studies identified changes in practice during the period of the curriculum reform in those selected schools. The interactions among the teacher librarian and the key change agents, namely the PSMCD and the principal were explored. Finally, the case studies investigated attempts made by the teacher librarians to move their practice towards that outlined in the Employment and Manpower Bureau documents, noting successful strategies, and roadblocks, to change.

Case study methodology was employed. Instruments included:

- A review of literature published by the Employment and Manpower Bureau with respect to the role of the teacher librarian

- A survey developed as a checklist of expected activities developed from the promulgated documents from the Employment and Manpower Bureau

- A semi-structured interview protocol

- Examination of school documents 
The study employed both quantitative and qualitative forms of analysis. This paper reports on the quantitative data.

\section{Implementation Factors}

What are the key factors that inform successful teacher librarian practice? The literature provides pointers to both outside school and inside school factors. Haycock (2001, 2002) provides a good summary of many of these factors which include: A policy framework, allocation of adequate resources, professional education and ongoing professional development opportunities, an articulated role statement and demarcation of professional, paraprofessional and clerical roles within the library, flexible scheduling of the teacher librarian, principal support and a collaborative culture.

Haycock (2002) spelt out a harsh reality that is well understood by teacher librarians beyond the confines of his Canadian study. He noted that:

It is a dilemma for teacher librarians to confront the gap between policy and practice. Although this is experienced every day as the curriculum written is not the curriculum delivered, it is nevertheless disconcerting to realize that what government says is not necessarily what government does. Advocacy efforts by teacher librarians will need to acknowledge that government documents often reflect best practice but that government funding often reflects political realities or just plain ignorance. This needs to be understood when seeking support for the implementation of best practice in schools. The dilemma is to find means to work with government and school district agencies in constructive, collaborative ways to integrate "best practice" with actual practice. This need for advocacy, that is, developing support and understanding incrementally over time, will require a planned, deliberate and sustained approach, over time, and will be a long and arduous process but must be seen as an integral part of education for teacher librarians and of the teacher librarian's work day.

The importance of an articulated teacher librarian role statement has dominated the teacher librarianship professional and research literature for at least five decades. A relatively recent example provided by Lupton (2002) attempts to identify shifts in recent practice.

The issue of provision of education for teacher librarians has likewise discussed for decades. An early example is provided by Kingsbury (1975) and a more recent ones by Lee, Brown, Mekis, \& Singh (2003) and Morizio \& Henri (2003).

The importance of adequate funding is perhaps a given but it is nevertheless vitally important. No matter how grand the impact of a school library, and the evidence of that impact, on teaching and learning it is almost certain to face the grim reaper in times of reduced funding. A famous example of this was delivered by the Calgary Board of Education, a world leader in the practice of school librarianship that had invested heavily during the 1970s in school libraries, as well as in the evaluation of their impact (demonstrating positive impact) only to find those same innovations to be decimated by government during financial hard times. 
The importance of an articulated policy framework has long been considered fundamental to the success of specialist teachers. Evidence for this belief was provided in a number of papers in the January 2006 issue of school libraries worldwide under the theme of policy: empowering school libraries.

Kuhlthau (1993) in her focus upon inside factors articulated the key enablers and key inhibitors of best practice. She found three primary inhibitors in programs that seemed to have stalled, that is, to have been unable to develop effective collegial teaching and learning: lack of time; confusion of roles; and poorly designed assignments. Stalled programs show evidence of lack of time both for instructional planning and for students to engage in information literacy activities. The lack of instructional planning prevents the development of new or enhanced instructional roles: the teachers give the assignments; the librarians find the resources; and the principal is not involved at all. The student assignments are not integrated into the classroom curriculum; they are often regarded as add-ons, as optional enrichment activities, rather than an essential part of curriculum-based learning.

Kuhlthau found that four basic enablers were present in successful programs: a team approach to teaching; a shared understanding of learning as a constructivist process; a shared commitment to lifelong learning; and competence in developing learning activities and strategies. Successful programs show evidence of the teachers, the librarian, and the principal working together to facilitate, develop, and implement instructional programs. Each person on the instructional team has essential roles to play - finding time for the instructional team to work together, ensuring that the assignments fit within the school's philosophy and goals, designing the assignments on an information process model, ensuring that the appropriate information resources are available, teaching the required information skills, and monitoring and assessing student work. The instructional team understands that students bring different understandings to their learning and that their new learning builds on what they already know; the team engages students in problem-based inquiry as one way for students to learn how to learn. The instructional team is focused on helping students to take responsibility for their own learning and to develop the skills for learning that are essential within and beyond the school. The instructional team develops assignments through innovation and experimentation; they are trying new approaches in order to enhance student learning.

\section{The Hong Kong setting}

The importance and provision of school libraries and of qualified teacher librarians in Hong Kong has been a given during the period of education reform that commenced around 1998. The reform identified the teacher librarian as a key agent of change.

In 2001 the Curriculum Development Council released the discussion document Learning to Learn - The Way Forward in Curriculum which articulated a very central and progressive role for the teacher librarian as an agent of curriculum change. 
Our vision for school libraries is that they should empower each student to attain information literacy through collaborative teaching and resource-based learning. We recognise the importance of having professional full-time teacher librarians in schools and expect each of them to play a new role as information and media specialist, teaching partner, curriculum change agent and learning and teaching resources coordinator.

Strategies to support library development include:

- $\quad$ Promoting resource-bases learning through a collaborative planning and teaching (CPT) "seed" projects

- Developing an interactive problem-solving and skill-learning web site known as "Internet Hunt" for Primary 3 to 6 students

- Developing and maintaining an updated reading list on recommended materials across the school curriculum

- $\quad$ Providing a web-based sharing database on library materials to facilitate cataloguing work among schools

- Assisting schools in library automation

- $\quad$ Seconding teacher librarians to the Library Section of the ED to support schools without central libraries

To enhance teacher librarians' professionalism, the following measures have been drawn up:

- $\quad$ Refresher workshops/courses for all serving teacher librarians

- A resource pack to be developed embodying practical ideas for school heads/principals, teachers, teacher-librarians, parents and students, on how to make effective use of library and information services for promoting learning to learn among students

- Annual induction for all new teacher librarians

- Close liaison with professional associations and tertiary institutions on latest developments, and with the Leisure and Cultural Services Department on the interface between public and school libraries, to promote the collaboration between teacher librarians and teachers

The curriculum development council (2002) reinforced its strong position on the role of the teacher librarian as an agent of change:

The role of a teacher-librarian has evolved from that of "keeper of the books" to "information specialist". A teacher-librarian, besides planning and managing the daily operations of the school library, plays the key role as a:

- $\quad$ reading resource and programme coordinator: coordinating and managing reading materials and curriculum-related resources to support the development of reading and of learning through reading 
- $\quad$ information and media specialist: developing students' information skills and attitudes in using information from all formats and contexts appropriately and ethically

- $\quad$ teaching partner: supporting the studies in Key Learning Areas, teaching and assessment

- $\quad$ curriculum facilitator: working with teachers to identify student needs, required curriculum content, appropriate information resources to develop school-based curriculum strategies such as project learning and life-wide learning activities

This expected role in curriculum planning and implementation is illustrated in Fig 1 below which is unambiguous in its expectation that if the shift towards a student centred curriculum is to become a reality then the teacher librarian ought to place priority on teaching and learning.

These policy documents are not mere announcements of a grand plan but were backed up by a series of interventions on the part of very senior members of the policy making apparatus. In her letters to principals and in her speech delivered to the IASL conference in Hong Kong in 2005 Fanny Law, the then Permanent Secretary, claimed that: 


\section{Students learn to learn}

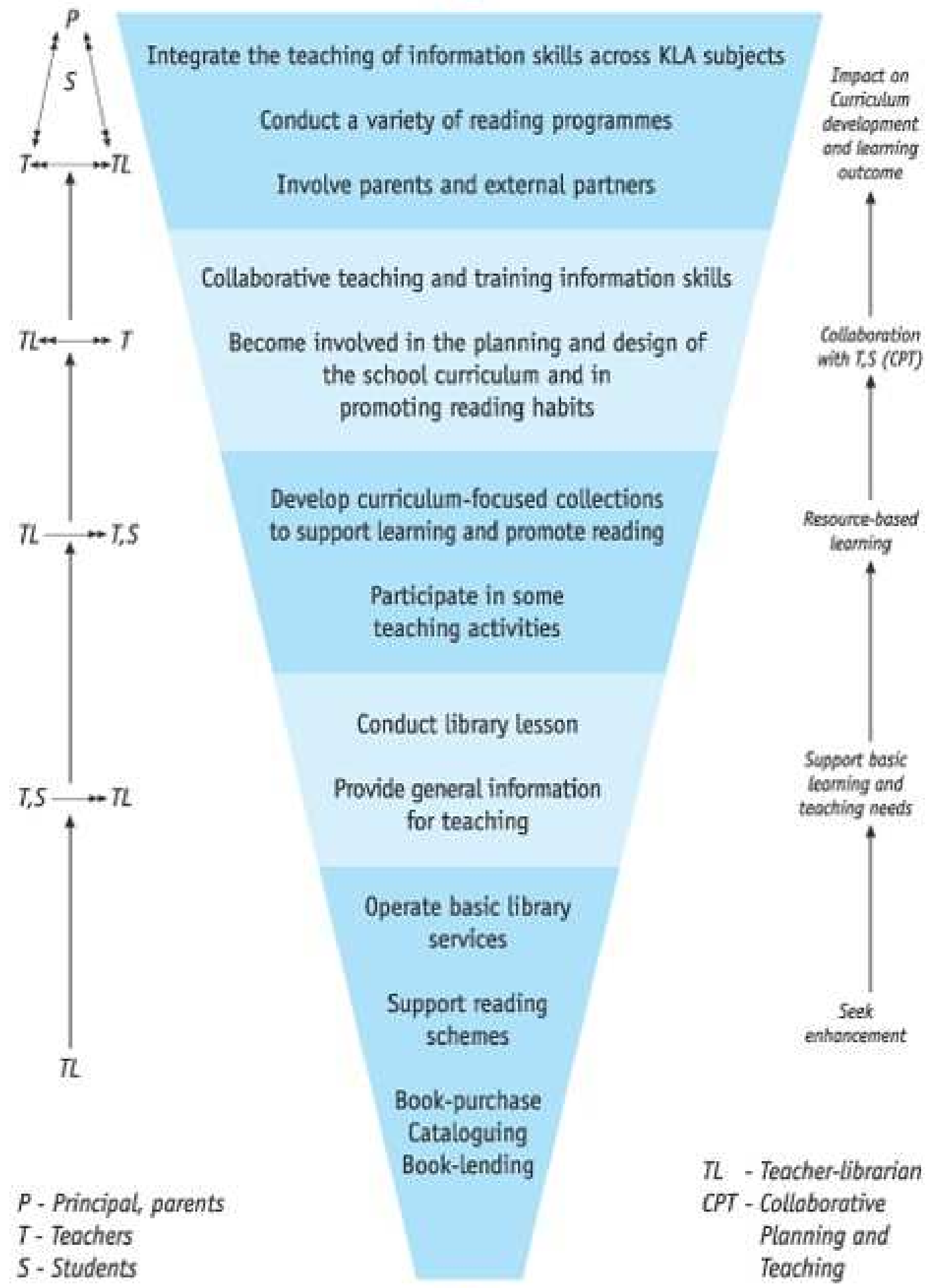

Teacher-librarian's involvement in learning is minimal

Fig. 1 Teacher librarian role. Basic Education Curriculum Guide, Booklet 7: 10

Retrieved from: http://cd1.emb.hkedcity.net/cd/EN/Content_2909/html/index.html 
The school library and teacher-librarians have a vital role to play in the new paradigm of teaching in the knowledge economy, building partnerships for learning and developing the school into an information community, where information and communication technologies support rather than override the educational goals. The job of the teacher-librarian is no longer restricted to managing the library collection. She is expected to be the information specialist, resources coordinator, teaching partner, curriculum facilitator, the role model on information literacy, and programme manager of reading schemes and inquiry-based learning.

In a nutshell, as the theme of this conference suggests, teacher-librarians have a significant part to play in providing "information leadership in a culture of change".

A crucial structural adjustment made by the Department of Education (later the Education and Manpower Bureau) was to reposition the 'Library Section' (now known as 'school library services' and positioned under the Resources and Support Team) which had largely assumed an inspectorate role, within the Curriculum Institute, that part of the EMB responsible for delivery of the curriculum reform.

In her presentation Fanny Law went onto mention some of the supports put in place by the Education and Manpower Bureau.

Since 2001, all schools in Hong Kong have been provided with a teacherlibrarian. Over the years, the government has worked hand-in-hand with the Hong Kong Teacher-Librarians' Association to provide induction training for new teacherlibrarians and continuing professional development for serving teacher-librarians. The government also scaled up the automation of school libraries, and sponsored the development of a standard bibliographic database to facilitate resources sharing and collaboration among school libraries.

Indeed almost all schools in Hong Kong that did not have a 'central' school library in 2001 now have one. Likewise funding is made available for collection development.

The EMB has been mindful of the need for close collaboration among policy makers and the key professional bodies and this has been a key feature of the relationship between the EMB and the Hong Kong Teacher Librarians' Association (HKTLA). Indeed, throughout the decade regular consultative meetings have been scheduled between the HKTLA and senior EMB officers. Tangible evidence of the outcome of this collaboration can be seen in the support provided by the EMB to sponsor approximately 300 teacher librarians to attend the 2005 IASL conference which was held in Hong Kong with the support of the HKTLA. Further evidence is provided by the fact that the HKTLA has been invited to provide input into a variety of EMB committees and initiatives.

As noted above the EMB has provided tangible support for professional training of teachers who become teacher librarians. The EMB is currently seeking tender bids for the eighth intake into the EMB sponsored Diploma in Teacher Librarianship program that is managed by the University of Hong Kong. This diploma is a part time 
program conducted over two years. In 2005 the EMB mandated that all new teacher librarians must complete the first year of the program in order to continue in the position. Of the 87 teachers who commenced the program 40 continued into the second year. In 2006 this mandate was extended to cover the entire program.

\section{Methodology}

A survey instrument including both open and closed questions was mounted on the web at http://www.my3q.com/home2/142/bchu/99518_viewData.phtml?record=44 and the newly appointed teacher librarians (2005 and 2006) involved in the Diploma in Teacher Librarianship program were encouraged to complete the survey. 104 respondents from a possible 109 new teacher librarians, or $94 \%$ of the candidates, took up the request. This represents $10 \%$ of all secondary school teacher librarians and $9.5 \%$ of all primary school teacher librarians. Data were collected and analyzed via Microsoft Office Excel.

\section{Results}

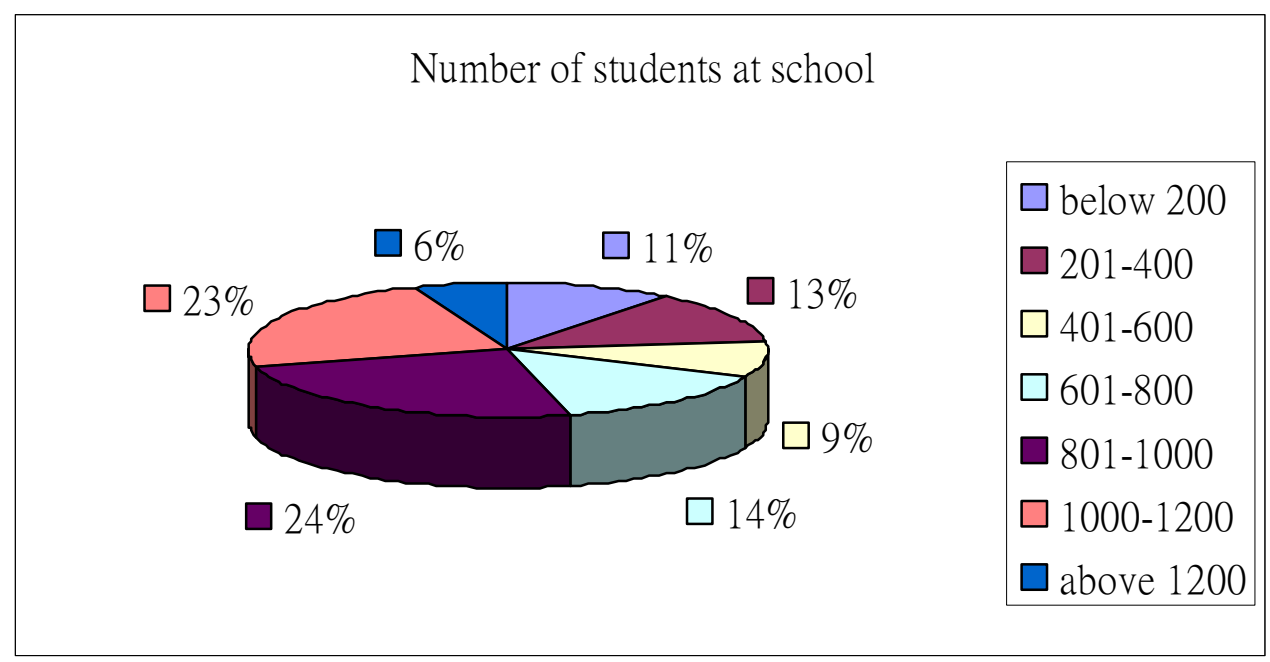

Most new teacher librarians are placed in quite large schools. 23\% are appointed to small schools where it might e argued that a part time deployment would be sufficient.

$65 \%$ of the teacher librarians are very experienced teachers whereas $14 \%$ had virtually no teaching experience (beyond the one year that is required) when they were appointed to the position of teacher librarian. 

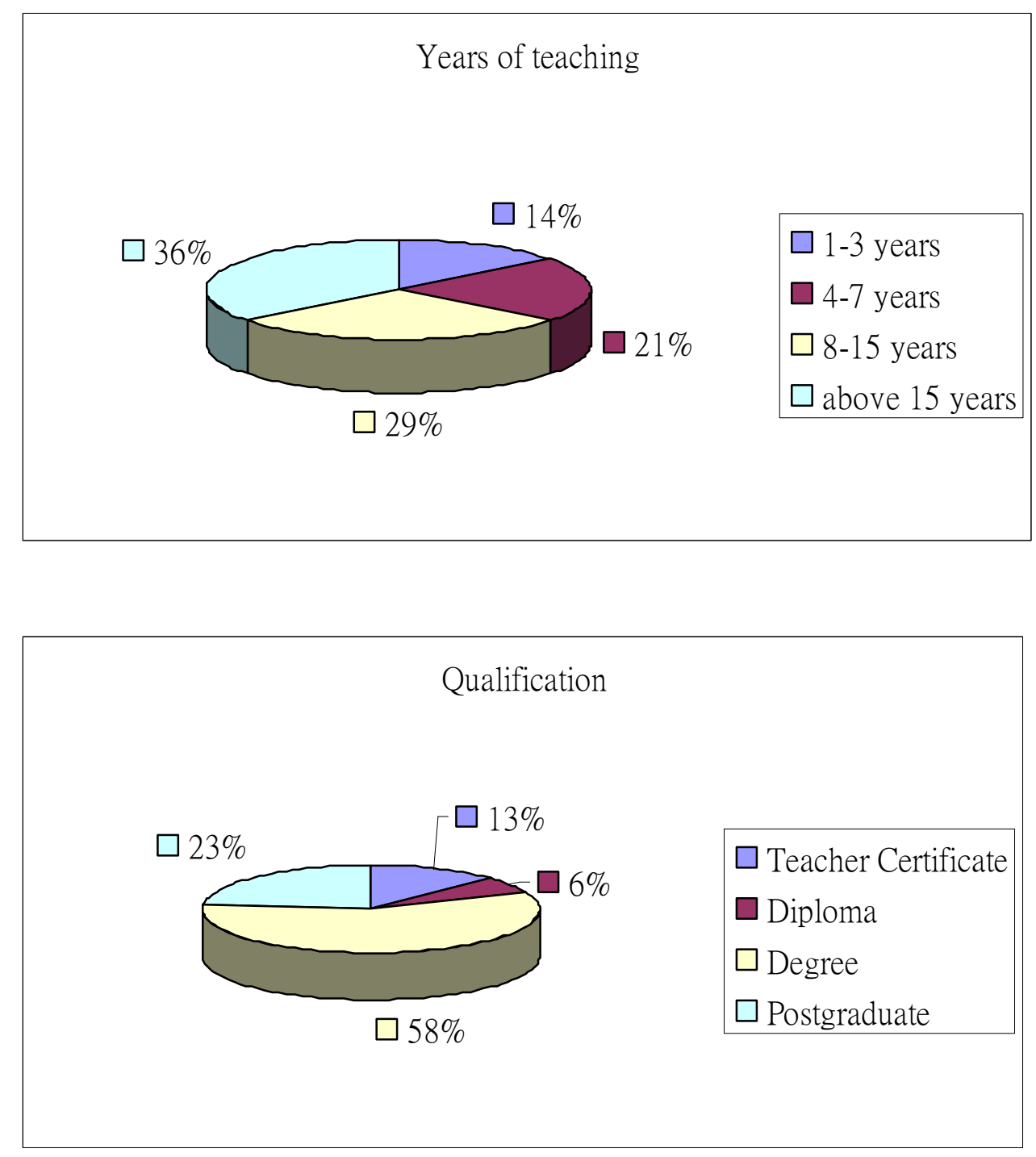

The teacher librarians are well qualified relative to other teachers in Hong Kong schools with just $19 \%$ of them not having completed a four year degree. 


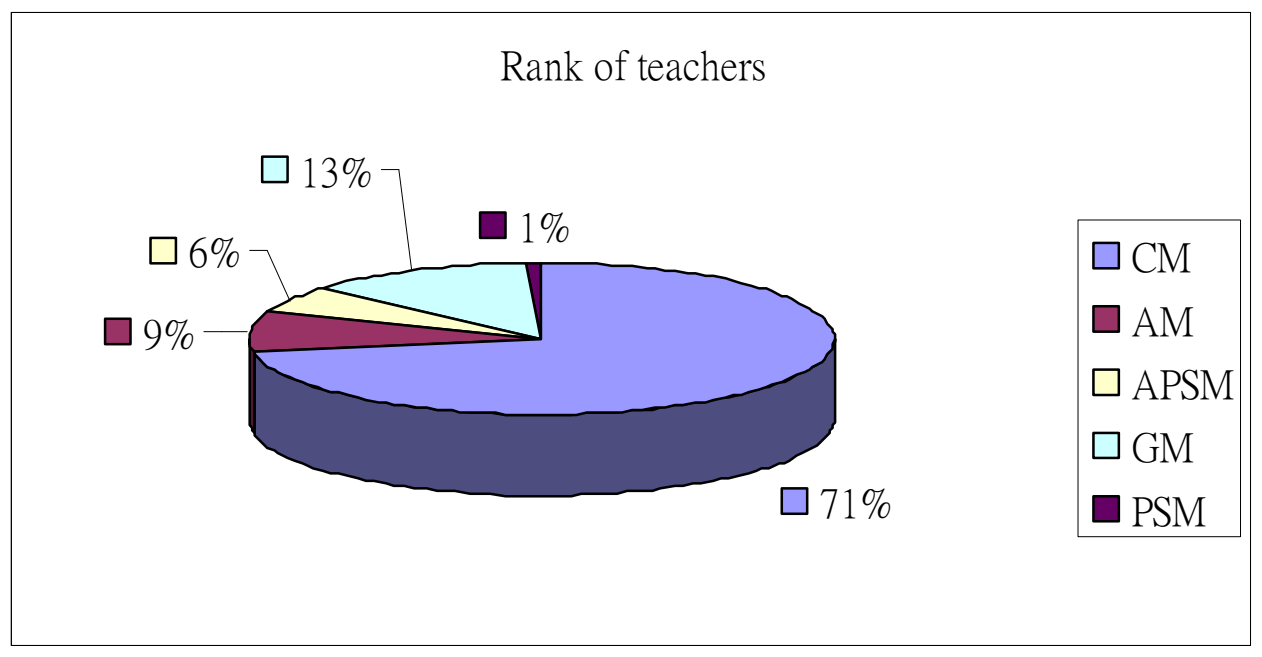

$71 \%$ of the teacher librarians are appointed at the lowest teaching rank with just $10 \%$ in senior positions. Given their qualifications and years of experience this is somewhat unexpected. Given the enormity of the challenge that the curriculum reform places on teachers one might expect that only highly motivated and experienced teachers would take on the challenges associated with the role of the teacher librarian. It might be suggested that principals have pushed these teachers into the library because they are seen as under-performing in the classroom, rather than because they are seen as energetic, resourceful and visionary teachers. But the data shows that just $22 \%$ of these teacher librarians were reluctant inheritors of the post.

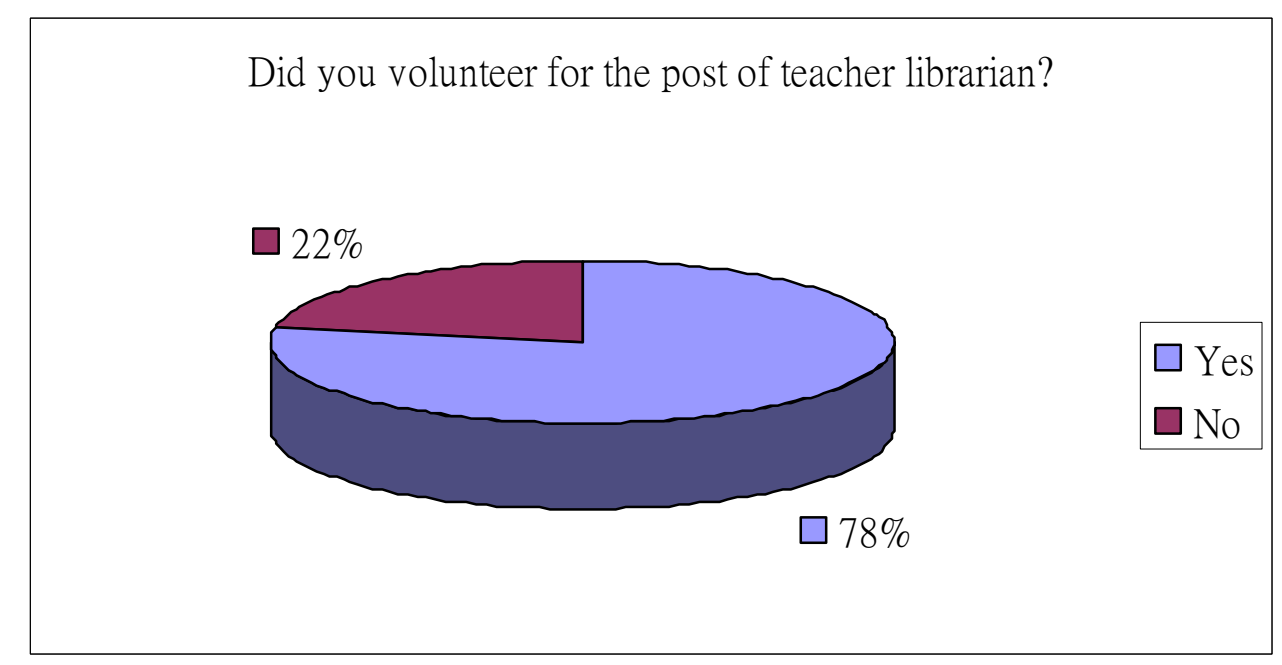

Despite the fact that the post of teacher librarian is supposed to be full time the data indicates that only $29 \%$ of these new teacher librarians are in fact full time. $9 \%$ of the teacher librarians are teaching a staggering 21 or more subject lessons per week. Again only $61 \%$ of the teacher librarians have support of a clerical assistant and then usually only on a part time basis. This means that the teacher librarian often has to 
spend much of the time that remains to them after teaching subject lessons and library lessons on shelving and other maintenance tasks.
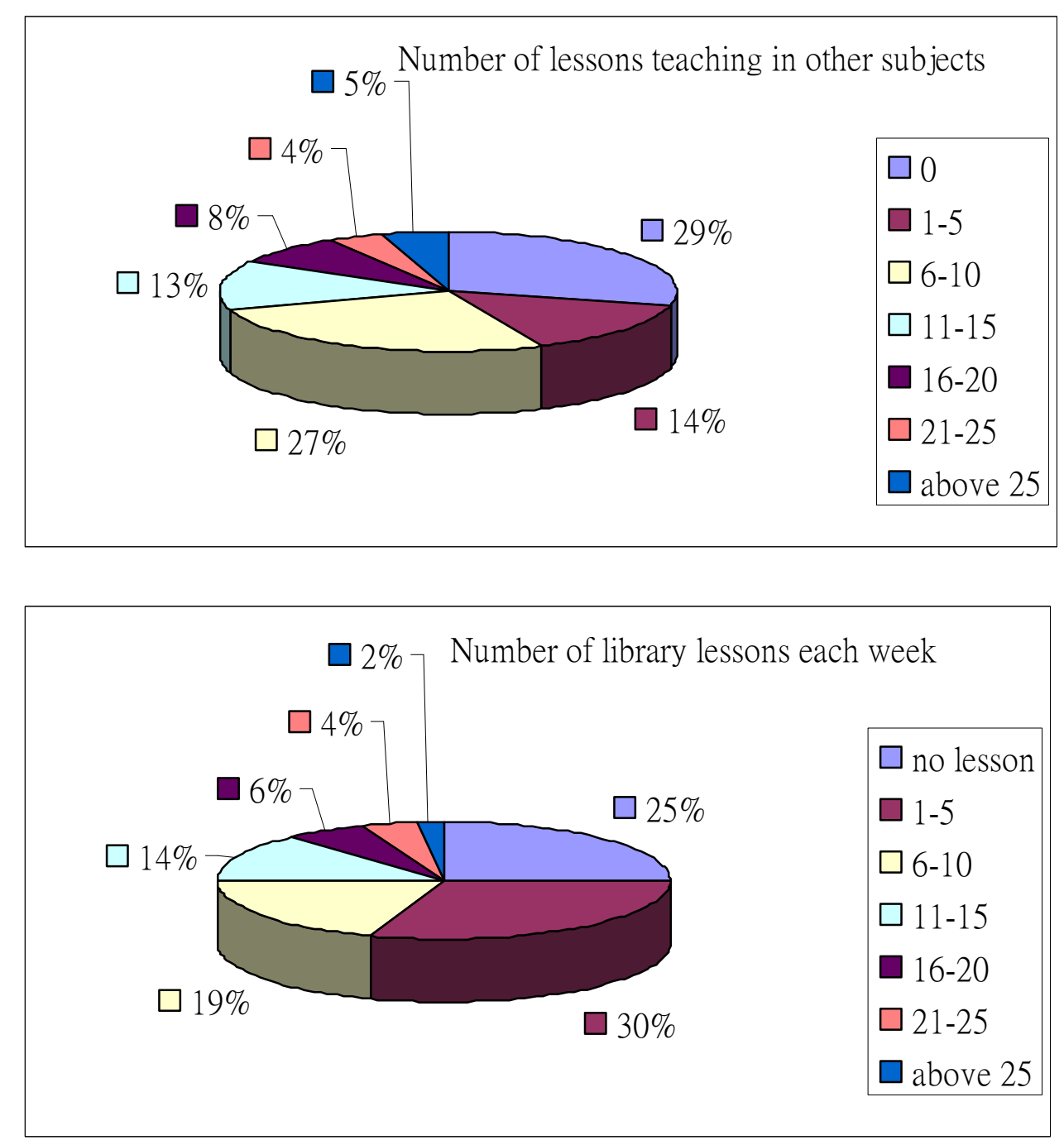

The large majority of teacher librarians are conducting library lessons in isolation from the curriculum. Indeed the vast majority of time within these lessons is focused upon reading and related activities or upon library skills in isolation.

Question 13: Please describe what sorts of things you do in these lessons.

\section{About library service}

Library introduction/ rules

Classification/ cataloguing / circulation 


\section{Information literacy}

Searching skills

24

Use of Internet

1

Information seeking and organizing

1

\section{Reading}

Teach reading strategies/ skills

Book talk/ recommendation

Share reading with children

Story reading

Promoting reading activities

Role play/ Drama

Character analysis

News sharing

\section{Teaching}

Theme based learning 1

Book report skills 2

Teach students to write reference book list 1

Thinking method 1

Collaborative teaching 2

Library skills 19

Are you responsible for "Reading to Learn" in your school?

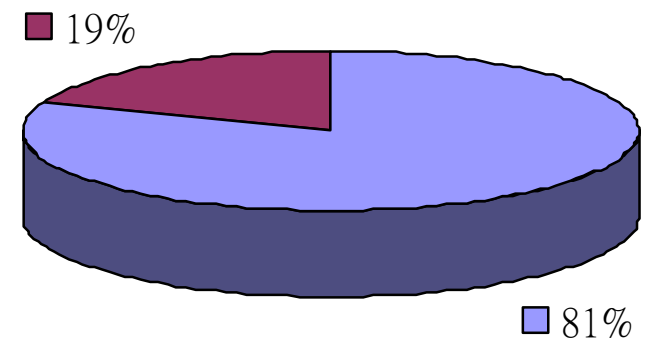

Schools are identifying the teacher librarian as the person who should deliver the EMB policy thrust on reading to learn. 
The responses to question 34 illustrate the ways that the teacher librarians are employed beyond their realm of expertise. These assigned responsibilities are often extremely time consuming and result in the teacher librarian spending very little time on core business.

\section{Question 34: What other non-library duties have you been given}

\section{Administration}

Insurance officer

IT coordinator/ web administrator

Finding substitute teacher

Grant proposal writing

Subject panel chair

\section{Committee member of}

Parent Teacher Association (PTA) 3

Curriculum development/ Teaching \& learning team 6

Staff development/ recreation team 4

School development/ administration team 4

\section{Teaching}

Class/ Form/ Subject/ Substitute teacher

Special Education Need (SEN) teacher

\section{School activities}

School promotion program (newsletters/bulletin) 4

Extra curriculum/ project 9

Environment education 2

School campus TV 1

\section{Student affairs}

Lunch box / tuck shop / lockers coordinator 6

Counselling/ disciplinary duties 4

Student health affair 5

Writing student's testimonials 1

The data shows that the teacher librarian focus is upon students. Given the subject teaching loads together with the high number of library lessons that are conducted it is not perhaps surprising that the teacher librarian is very isolated from 
teaching colleagues and is therefore unable to deliver the EMB policy with respect to their preferred role.

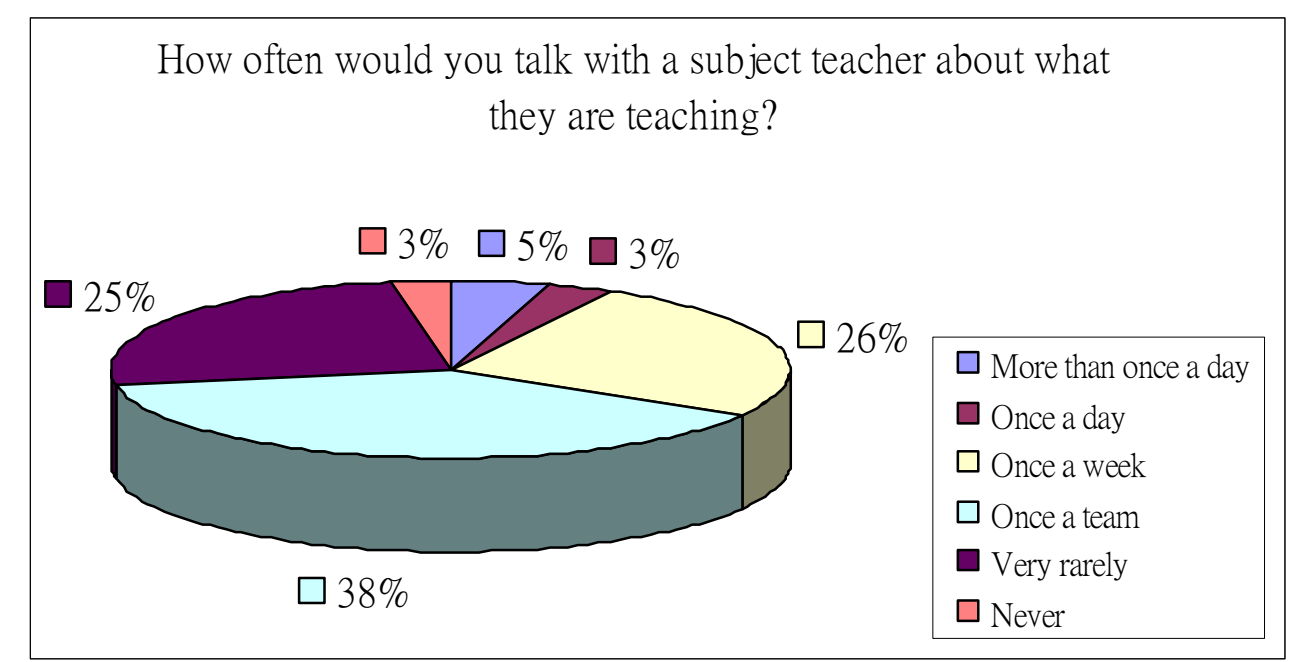

In fact the teacher librarians have little day to day contact with teachers and this gravely inhibits their role as an agent for change.

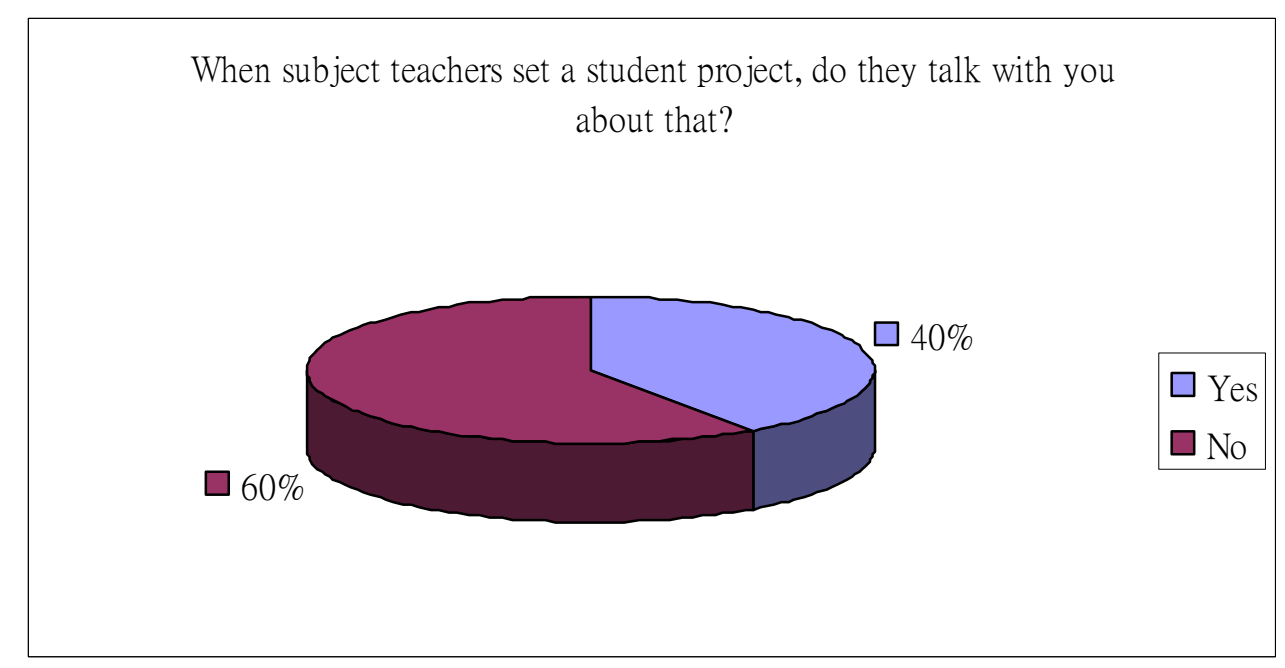

The majority of teachers do not even consider the teacher librarian as a resource to be employed when setting up project work and the predominantly short length of lessons militates against the adoption of student centred pedagogies and therefore minimizes the perceived need to involve the teacher librarian and indeed limits the possibility active intervention from the teacher librarian. And the data suggests that the teachers are not making use of the library. 


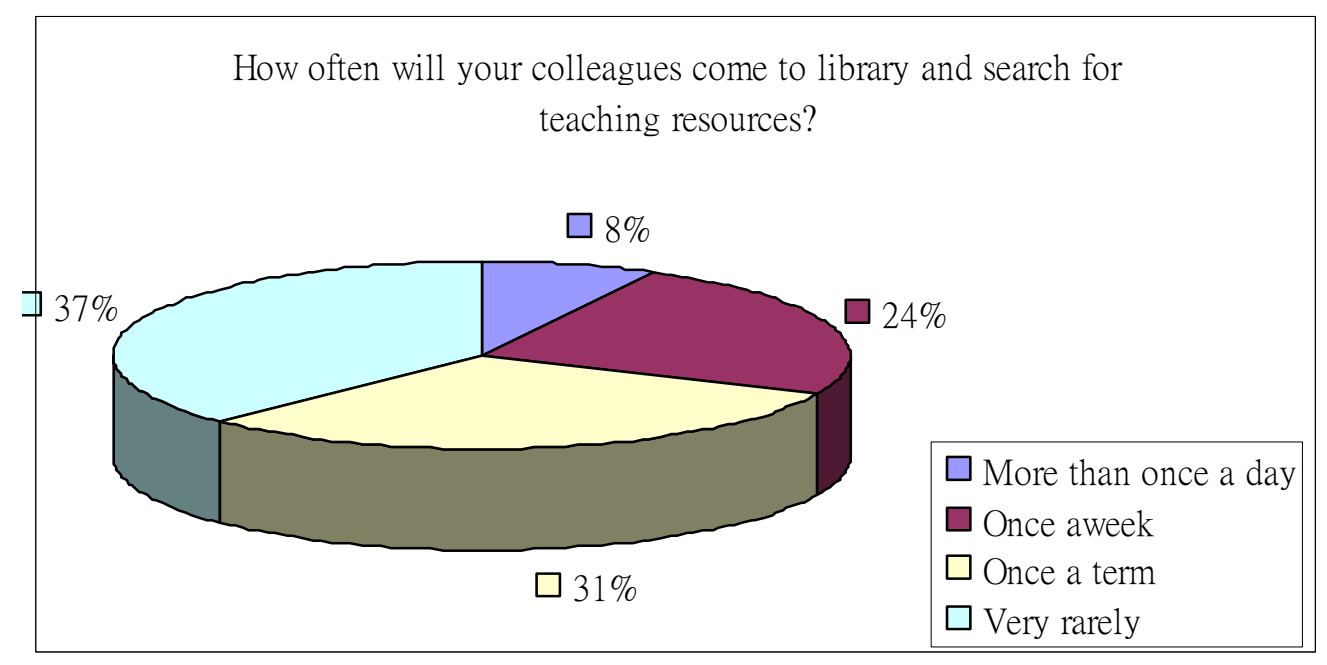
principal.

$78 \%$ of the teacher librarians report directly to the principal or to the vice

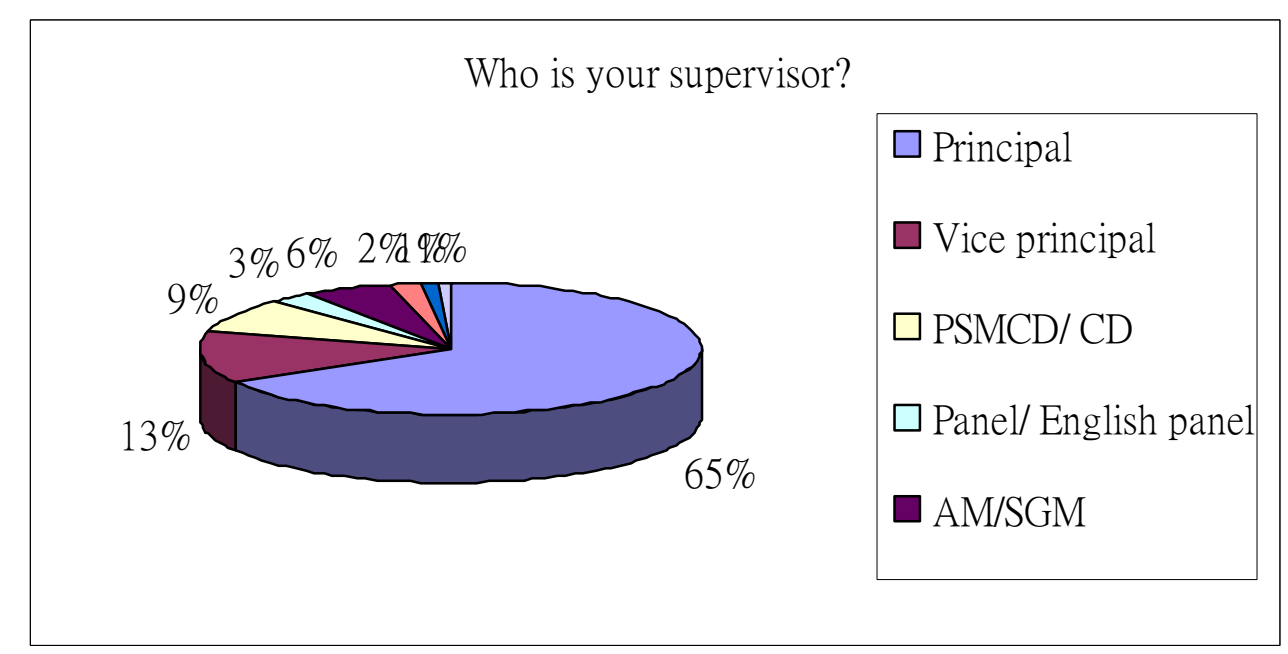

Yet the data shows that direct communication between the school leadership and the teacher librarian is rather limited. $57 \%$ of the teacher librarians meet with the principal just once a term or even more infrequently. This infrequent meeting contact is mirrored by the principal's visits to the library. 

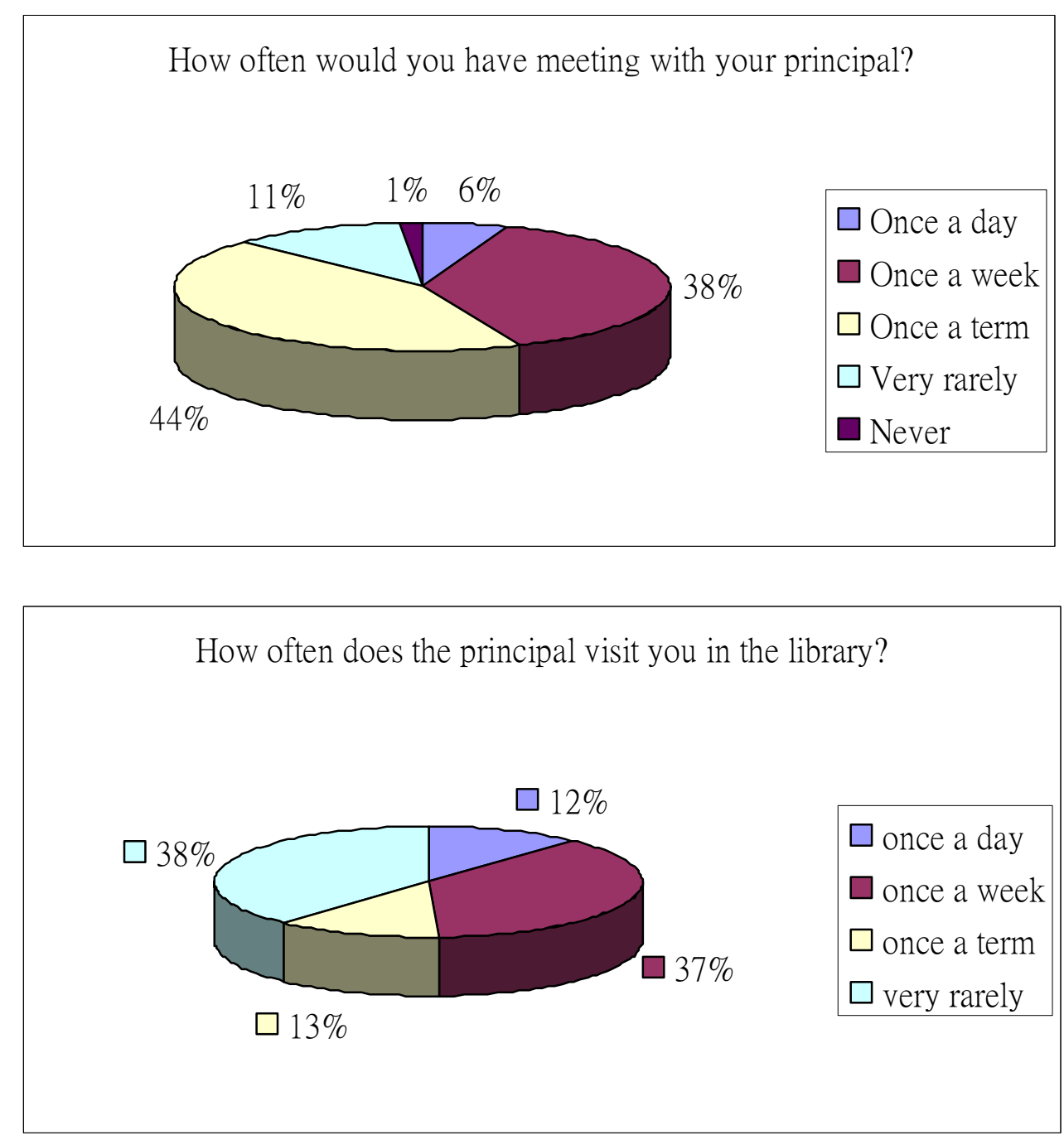

A majority of schools have a library web presence but this tends to be managed by the teacher librarian; they under-employ the teacher librarians in terms of curriculum development, and they have not developed information policies. 


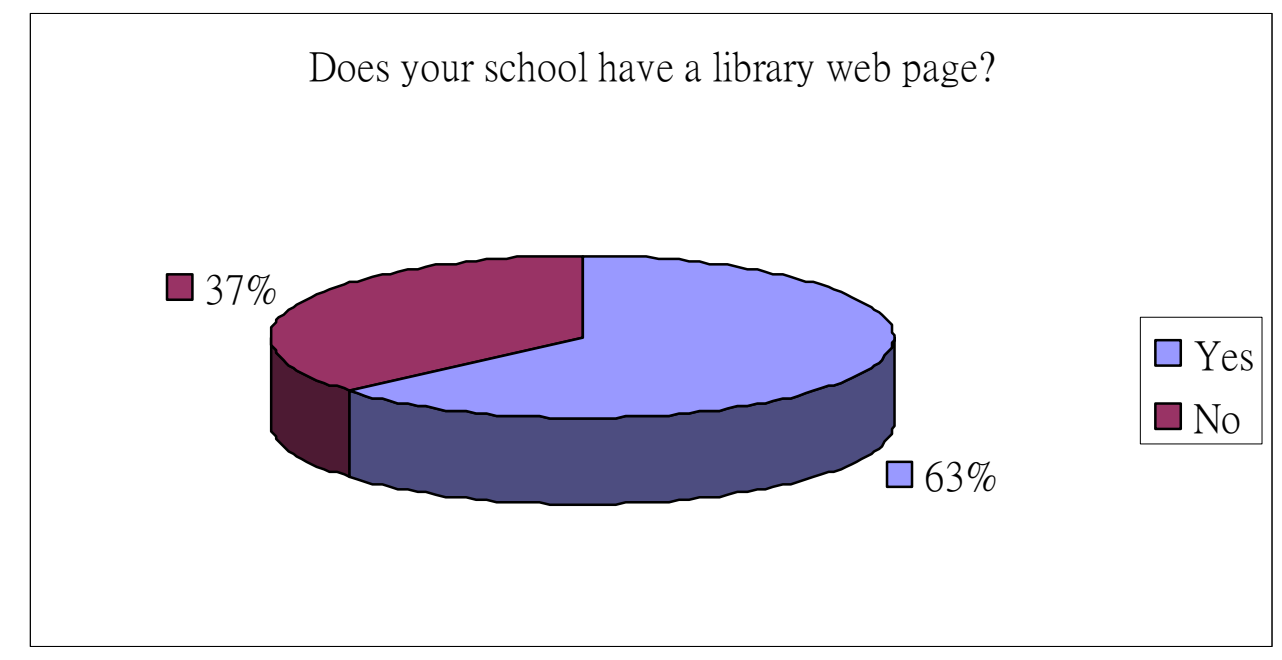

The sponsorship of the teacher librarians by the EMB into the diploma program comes at a cost to schools who must agree to release the staff to attend some lessons that are scheduled on week days. In practice support is often not so forthcoming as the following suggests.

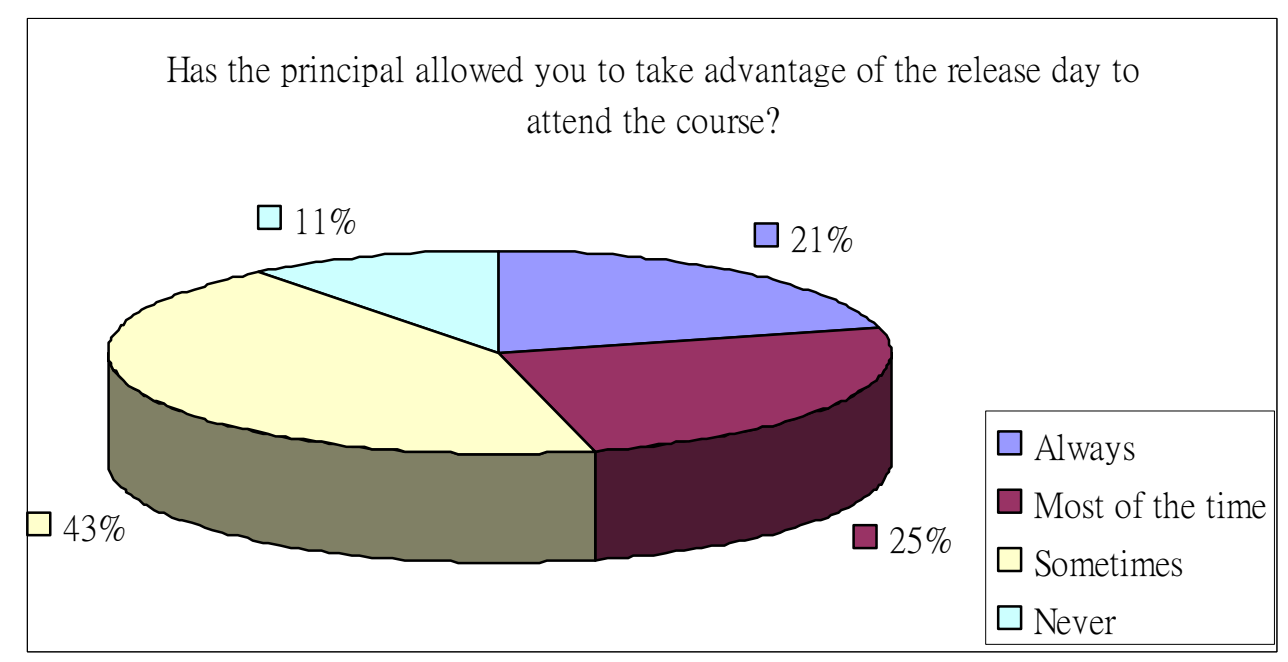

Given that the EMB is investing heavily in the infrastructure of school libraries and the training of teacher librarians one might expect that EMB officers from the Library Section might visit these newly appointed teacher librarians to monitor and evaluate the situation. However this is clearly not happening as the following illustrates. 
Since you have been a teacher librarian have you been visited

by an EMB Officer with knowledge about your role?

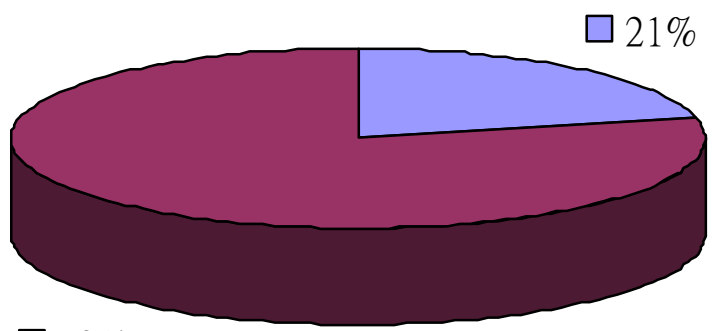

$79 \%$

The participants were asked to self assess their progress against the EMB's road map for school library development as given in Fig. 1. above. A score of 1 was allocated to the bottom rung and a score of 5 to the top rung.

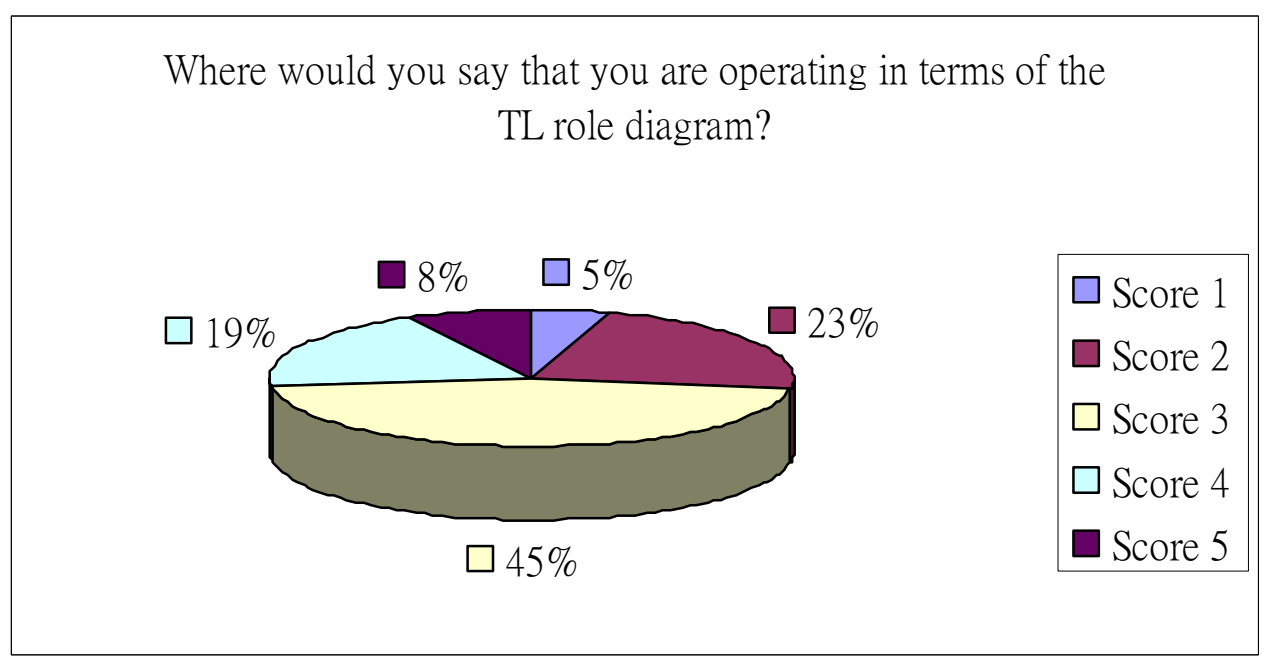

The mapping illustrates a somewhat optimistic view. It would be fair to say that the data would suggest that few of the participants are operating above level 2 . The focus is almost entirely at students rather than teachers, while the research suggests that change in school culture will only mature out of change in teacher practice (Fullan 2001; Fox and Henri 2005). The vast majority of schools have provided access to the library by way of a fixed timetable and lessons are generally too short to enable subject teachers to make meaningful use, of a visit to the library, or even of information resources that would enable effective use of student centred pedagogies. 


\section{Conclusions}

There is much to like about the curriculum reform that is unfolding around Hong Kong schools. The Hong Kong government through the EMB has invested significant funds in infrastructure and the creating of new teaching positions that are essential to drive teaching and learning from the textbook and the test to the student and enquiry learning. In the case of school libraries and the deployment of teacher librarians the EMB scores very high marks in fundamentals such as policy, role articulation, training provision, and funding. So why is the state of affairs so lacking in optimism?

The following observations are offered:

The post of teacher librarian is mandated but a principal can move a teacher in and out of the post at whim. The remedy is simple. The EMB could require that new teacher librarians be appointed for a minimum period of time such as 3 or 5 years. This would avoid the constant turnover of staff, would consolidate knowledge and would save money on training.

Schools are allocated a teacher librarian as an 'excess to quota' position. In addition the post of teacher librarian is full time in theory only and therefore the incumbent is spread across a myriad of responsibilities. This is an impossible situation even for highly competent teachers and quite impossible for a teacher librarian in training. The result is that the focus is not on the role of the teacher librarian. Again the EMB could deal with this by requiring that principals who do not deploy their teacher librarian on a full time basis lose the post.

The position of teacher librarian is flagged by the EMB as essential to curriculum reform but very junior staff are filling the position. The EMB could tighten the criteria for appointment to the post and ensuring that the successful candidate is a well qualified, innovative and respected teacher. A percentage of positions could be earmarked as senior.

Whereas the curriculum reform suggests that teacher librarians should be working with teachers their focus is almost entirely on students whom they teach in isolation. The EMB could address this issue by targeting the school leadership and by funding experimentation in administration of the timetable and ensuring suitable access to the teacher librarian through the provision of teacher planning time. Principal and school appraisal could e adjusted to reflect the importance of teacher and teacher librarian collaboration.

The EMB is informed by the school library services team (formerly known as the Library Section) but this team lacks expertise in school librarianship. If this team is to be recognized and supported within the EMB it should be managed by experienced 
school library professionals in much the same way that experienced professional take a leadership role in the organization of other support areas.

\section{References}

Fox, R., \& Henri, J. (2005). Understanding teacher mindsets: IT and change in Hong Kong schools. Educational Technology and Society, 8(2), 161-169.

Fullan, M. (2001). Leading in a Culture of Change. San Francisco: Jossey-Bass.

Haycock, K. (2001). Reconceptualization and Reconfiguration of Expectations and Service Delivery Models: A review of the role of the teacher librarian and school library resource centre in School District \#39 (Vancouver): Vancouver (British Columbia) School Board.

Haycock, K. (2002). Strategic directions and newer dilemmas for teacher-librarians and school library resource centres. School Libraries in Canada, 22(2), 14-15.

Kingsbury, M. E. (1975). Education for school librarianship: expectation vs. reality. Journal of Education for Librarianship, 15(4), 251-257.

Kuhlthau, C. C. (1993). Implementing a process approach to information skills: a study identifying indicators of success in library media programs. School Library Media Quarterly, 22(1), 11-18.

Lee, S., Brown, G., Mekis, C., \& Singh, D. (2003). Trends and issues from selected developing countries. Paper presented at the 69th IFLA General Conference and Council. from http://www.ifla.org/IV/ifla69/papers/069e-Lee_Brown_Mekis_Singh.pdf.

Lupton, M. (2002). The getting of wisdom: reflections of a teaching librarian. Australian Academic \& Research Libraries, 33(2), 75-85.

Morizio, C., \& Henri, J. (2003). Education for school librarianship: selected issues and trends. Paper presented at the 69th IFLA General Conference and Council. from http://www.ifla.org/IV/ifla69/papers/125e-Morizio_Henri.pdf.

\section{Policy documents}

Cheng, M. Y. (2001). Administration circular No.30/2001: Provision of teacher librarian in aided school. Hong Kong: Education Department. from http://www.emb.gov.hk/FileManager/TC/Content_3924/ad01030e.pdf

Curriculum Development Council. (2001). Learning to Learn: The Way Forward in Curriculum Development. Hong Kong: Curriculum Development Council, 2001. from http://cd1.emb.hkedcity.net/cd/EN/Content_2908/e05/chapter5.pdf

Curriculum Development Council. (2002). "Booklet 3B: Reading to Learn." Basic Education Curriculum Guide: Building on Strengths (Primary 1 - Secondary 3). Hong Kong: Curriculum Development Council. from http://cd1.emb.hkedcity.net/cd/EN/Content_2909/html/index.html

Curriculum Development Council. (2002). "Booklet 7: Quality Learning \& Teaching Resources \& School Library Development". Basic Education Curriculum Guide: Building on Strengths (Primary 1 - Secondary 3). Hong Kong: Curriculum Development Council, 2002. from http://cd1.emb.hkedcity.net/cd/EN/Content_2909/html/index.html

Curriculum Development Council. (2002). Reading to learn: School library services support learning and teaching. 《學會學習：學校圖書館服務支援學與教》Hong Kong: Curriculum Development Council. (Chinese only). from http://cd.emb.gov.hk/lib/school_lib/learn_teach/lt.htm

Ip, Betty. (2003). Circular memorandum No.54/2003: Provision of teacher librarian to aided special schools. Hong Kong: Education and Manpower Bureau. from http://www.emb.gov.hk/FileManager/TC/Content_3924/embcm03054e.pdf 
Law, F. (2002). Letter from the Permanent Secretary for Education and Manpower Bureau on

"Promotion of Reading Culture in School". Hong Kong: Education and Manpower Bureau. from http://www.emb.gov.hk/FileManager/TC/Content_3924/readingculturee.pdf

Law, F. (2005). Welcome address to $34^{\text {th }}$ International Conference of School Librarianship. from http://www.emb.gov.hk/index.aspx?nodeID=134\&langno=1\&UID=101815

School Library Services. (2006). Exemplars of school library services(圖書館好, 學校好一學校圖書館 服務示例) (Chinese only). Hong Kong: Education and Manpower Bureau. from http://www.emb.gov.hk/index.aspx?langno=2\&nodeID $=5575$

School Library Services (2001). School library services statistic and data collection in Nov., 2001 (Chinese only). Hong Kong: Education and Manpower Bureau. from http://cd.emb.gov.hk/lib/tl/hkslibsurvey.pdf (combining secondary and primary data) http://cd.emb.gov.hk/lib/school_lib/schlib_info/survey/survey_main.htm

\author{
Author Note \\ James Henri \\ Associate Professor \\ The Faculty of Education \\ The University of Hong Kong \\ jameshenri@hku.hk \\ Chu Wah Hing, Betty \\ Part-time Tutor HKUSPACE, University of Hong Kong \\ Commissioner, Hong Kong Teacher Librarians' Association \\ Teacher Librarian \\ Tsing Yi Trade Association Primary School \\ bchu05@yahoo.ca
}

